\section{A probable case of anti-NMDAR encephalitis from 1830}

Neurol Neuroimmunol Neuroinflamm November 2020 vol. 7 no. 6 e901. doi:10.1212/NXI.0000000000000901

This issue of N2 highlights the diversity of autoimmune disorders that affect the nervous system. Whether you are interested in $\mathrm{T}$-cell- or B-cell-mediated disorders or prefer white matter or gray matter, you will likely find an article of interest. In addition for the medical sleuths among our readers, we have the likely resolution of a 190-year-old unresolved diagnosis.

Bickerstaff brainstem encephalitis (BBE) is characterized by the acute onset of drowsiness, external ophthalmoplegia, and ataxia. Owing to its rarity, there are few large series describing its clinical and immunologic features. In this issue of N2, Yoshikawa et al. ${ }^{1}$ report the clinical characteristics of 83 patients with BBE and identify differences between GQ1b antibody positive and negative cases. Their results show that compared with antibody negative patients, those with GQ1b antibodies more commonly had a preceding upper respiratory infection and sensory disturbances (often dysesthesia), lower CSF cells counts and protein levels and were less likely to have abnormal MRI abnormalities. There were no differences in disease severity or response to treatment between the antibody positive and negative groups, although in the antibody positive group, the disturbance of consciousness resolved earlier. The authors postulate that the distinctive features of GQ1b antibody-positive patients suggest that the antibodies play a pathogenic role in BBE and determine its clinical characteristics. There are limitations to this study; of the 83 patients, only 10 were GQ1b antibody negative; clinical information was obtained retrospectively, and the presence of other antibodies was not studied. Nonetheless, this remains a large series of patients and supports a clinically homogeneous syndrome for GQ1b antibody-positive patients. Recognition of the syndrome with subsequent confirmation by antibody testing could facilitate diagnosis.

In another article, Broux et al. ${ }^{2}$ investigated the role of interleukin-26 (IL26) in MS, particularly in blood-brain barrier (BBB) integrity. It is strongly believed that after myelin-reactive $\mathrm{CD}^{+} \mathrm{T}$ helper $(\mathrm{TH})$ lymphocytes are activated by environmental triggers, they cross the $\mathrm{BBB}$ and initiate a chronic relapsing inflammatory process that leads to tissue damage. These TH lymphocytes produce multiple cytokines, such as IL-17 or IL-22, that are involved in BBB breakdown and others such as granulocyte macrophage colony-stimulating factor that activate a subtype of monocytes that promote tissue damage. In addition, IL-26 is a TH17-associated cytokine for which there is emerging evidence of its involvement in various immunologic diseases. In inflammatory diseases other than MS, such as Crohn disease or rheumatoid arthritis, IL-26 seems to play a proinflammatory role, whereas other studies have shown that it is involved in antibacterial host defences. Although the role of IL-26 in MS is largely unknown, Broux et al. postulated that IL-26 has a proinflammatory role including disruption of the BBB. To test this hypothesis, the authors used several experimental approaches including among other a $M O_{35-55}$ autoimmune encephalitis (EAE) mouse model, in which animals were given intraperitoneal injections of IL-26. First, the authors found that the concentration of IL-26 was elevated in serum and CSF of untreated patients with MS compared with controls and that IL-26- 
expressing $\mathrm{TH}$ lymphocytes were enriched in perivascular infiltrates in patients with MS, promoting BBB integrity. Moreover, in the animal model, they found that IL-26 showed protective effects in chronic EAE increasing the number of IL10 producing CNS infiltrating $\mathrm{TH}$ lymphocytes and reducing the number of pathogenic TH lymphocytes. The findings have potentially important therapeutic implications for patients with MS and should be validated in future studies.

Continuing with MS, it is currently known that genetic and environmental factors contribute to the risk of developing the disease $^{3}$ and among the latter, the Epstein-Barr virus (EBV) is the major infectious risk factor. Moreover, heritable factors influence the ability to develop immunoglobulin G (IgG) response to EBV nuclear antigen 1 (EBNA-1), suggesting that host-genetic factors are important in the immune response to MS. ${ }^{4}$ In this issue of N2, Mescheriakova et al. ${ }^{5}$ determined the titers of IgG antibodies against EBNA-1 in families of patients with MS, including patients with the disease, healthy siblings, and unrelated healthy spouses, and investigated the role of specific genetic loci of the viral antibody titers. The authors found an EBNA-1 antibody gradient, higher in patients (particular in younger cases), intermediate in siblings, and lowest in the spouses supporting a genetic contribution to EBNA-1 antibody titers; this was only partially explained by HLA-DRB $1^{*} 1501$ carriership. Future larger studies assessing MS genetics and EBNA-1 IgG responses are needed to characterize which MS risk single nucleotide polymorphisms are contributing to the enhanced EBNA-1 IgG response in patients with MS, and according to the data presented here, age will need to be considered.

For those of you who enjoy a good detective story and medical mystery, I will end this Editor's Corner with the contribution of Tényi et al. ${ }^{6}$ While reviewing the historical medical literature, these authors found reference to the same case report in medical journals published in Hungarian, German, and Italian. The case was presented at the 3 rd meeting of the Italian Scientists held in Florence in 1841. The patient presented in 1830 . She was a previously healthy 18 -year-old woman who developed seizures, followed by a 6-day-long clinical state characterized by catalepsy, unresponsiveness, and shallow breathing. These symptoms apparently resolved but returned over the following year and a half during which a progressively growing abdominal tumor was noted. One day, she suddenly developed emesis that included pus and blood mixed with more than 100 bone fragments. At the same time, she had evacuation from the anus and vagina of a membranous substance mixed with blood and pus. After this event, the seizures and the catalepsy-like episodes disappeared. Over the following years, she gave birth to 3 healthy children and was still well 11 years later. The authors suggest that this represents a case of anti-NMDA receptor (NMDAR) encephalitis. They postulate that the catalepsy-like state was catatonia, which was not defined as an entity for more than 40 years after this patient's presentation. They suggest that the mass was an ovarian teratoma, which can reach large sizes, contain bone and perforate into the bowel and vagina, whereas the shallow breathing was likely because of hypoventilation. The authors remind us that this description of a likely paraneoplastic syndrome from 1830 predates by 35 years that of Trousseau syndrome, which is considered the first paraneoplastic syndrome reported. The case is fascinating and reminds us of complications in patients with anti-NMDAR encephalitis (continuous tumor growth despite partial neurologic improvement and bowel perforation $)^{7}$ that were included in the first description of this disease and are now rarely encountered due early recognition of this disorder.

In addition to these 4 articles, the November issue of $\mathrm{N} 2$ contains 20 other interesting articles and 4 clinic/scientific notes that I am sure will catch your attention.

\section{Study funding}

No targeted funding reported.

\section{Disclosure}

J. Dalmau holds patents for the use of Ma2, NMDAR, GABABR, GABAAR, DPPX, and IgLON5 as autoantibody tests and receives royalties from the use of these tests. Go to Neurology.org/NN for full disclosures.

\section{References}

1. Yoshikawa K, Kuwahara M, Morikawa M, Kusunoki S. Bickerstaff brainstem encephalitis with or without anti-GQ1b antibody. Neurol Neuroimmunol Neuroinflamm 2020;7:e889. doi: 10.1212/NXI.0000000000000889.

2. Broux B, Zandee SEJ, Gowing E, et al. Interleukin-26, preferentially produced by TH17 lymphocytes, regulates CNS barrier function. Neurol Neuroimmunol Neuroinflamm 2020;7:e870. doi: 10.1212/NXI.0000000000000870.

3. Belbasis L, Bellou V, Evangelou E, Ioannidis JP, Tzoulaki I. Environmental risk factors and multiple sclerosis: an umbrella review of systematic reviews and meta-analyses. Lancet Neurol 2015;14:263-273.

4. Rubicz R, Yolken R, Drigalenko E, et al. A genome-wide integrative genomic study localizes genetic factors influencing antibodies against Epstein-Barr virus nuclear antigen 1 (EBNA-1). PLoS Genet 2013;9:e1003147.

5. Mescheriakova JY, van Nierop G, van der Eijk A, Kreft KL, Hintzen R. EBNA-1 titer gradient in multiple sclerosis families indicates a genetic contribution. Neurol Neuroimmunol Neuroinflamm 2020;7:e872. doi: 10.1212/NXI 0000000000000872

6. Tényi D, Szücs A, Kovács N, Illes Z, Janszky J. Paraneoplastic anti-NMDA-receptor encephalitis in 1830? Neurol Neuroimmunol Neuroinflamm 2020;7:e887. doi: 10 1212/NXI.0000000000000887.

7. Dalmau J, Tüzün E, Wu HY, et al. Paraneoplastic anti-N-methyl-D-aspartate receptor encephalitis associated with ovarian teratoma. Ann Neurol 2007;61: $25-36$. 


\section{Neurology \\ Neuroimmunology \& Neuroinflammation}

A probable case of anti-NMDAR encephalitis from 1830

Josep Dalmau

Neurol Neuroimmunol Neuroinflamm 2020;7;

DOI 10.1212/NXI.0000000000000901

This information is current as of October 21, 2020

\section{Updated Information \& Services}

References

Permissions \& Licensing

Reprints including high resolution figures, can be found at:

http://nn.neurology.org/content/7/6/e901.full.html

This article cites 7 articles, 4 of which you can access for free at: http://nn.neurology.org/content/7/6/e901.full.html\#\#ref-list-1

Information about reproducing this article in parts (figures,tables) or in its entirety can be found online at:

http://nn.neurology.org/misc/about.xhtml\#permissions

Information about ordering reprints can be found online: http://nn.neurology.org/misc/addir.xhtml\#reprintsus

Neurol Neuroimmunol Neuroinflamm is an official journal of the American Academy of Neurology.

Published since April 2014, it is an open-access, online-only, continuous publication journal. Copyright

Copyright $\odot 2020$ The Author(s). Published by Wolters Kluwer Health, Inc. on behalf of the American Academy of Neurology.. All rights reserved. Online ISSN: 2332-7812.

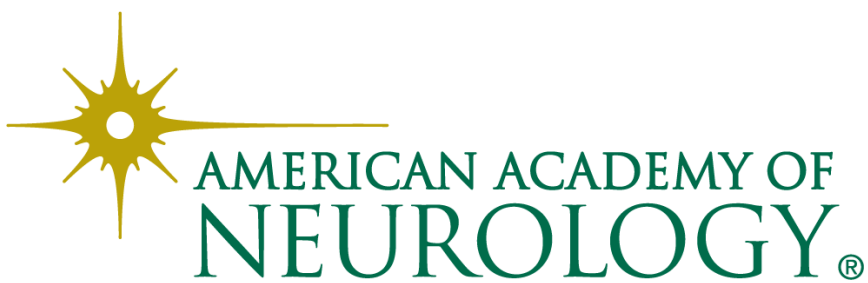

